\section{Supporting dental registrants in difficulty: the service provided by postgraduate dental education teams}

\author{
M. Pearce, ${ }^{* 1}$ S. J Agius, ${ }^{2}$ J. Macfarlane ${ }^{3}$ and N. Taylor ${ }^{4}$
}
IN BRIEF
- Explains why the service provided by postgraduate dental teams to registrants in difficulty have expanded significantly in recent years.
- Seeks to quantify the number of registrants seeking support from postgraduate teams and the number and types of supporters providing help.
- Discusses some possible ways that the support for registrants in difficulty could be developed in the future.

The number of dental registrants in difficulty (DRiDs) has increased significantly in recent years and the General Dental Council or National Health Service organisations tasked with the management of dental services will, if appropriate, instruct the registrant to contact postgraduate dental teams (PgDT) based in regional offices of Health Education England and equivalent postgraduate deaneries in Wales and Scotland for assistance in meeting their conditions for continued registration. We surveyed DRiDs Leads within the PgDT with a view to understanding the current development of this important service. Results revealed that these managers had considerable relevant previous experience which underpinned their responsibility for DRiDs. Their responses indicated that there were notable differences between PgDT in the number of DRiDs seeking their help and that the development of the service and the resources deployed to help DRIDs also differed significantly. Those responsible were generally happy with the service they were providing and all were able to see DRiDs for an initial interview within four weeks of being contacted. However, weaknesses were identified such as insufficient time to support individual registrants, lack of consistent process across PgDT teams and a need for clinical training facilities.

\section{THE RISING INCIDENCE OF DENTAL REGISTRANTS IN DIFFICULTY}

A UK dental professional operates within a heavily regulated environment. The General Dental Council (GDC) registers qualified dental professionals including dentists, therapists, hygienists, technicians and nurses. It sets and enforces standards of dental practice and conduct, protects the public from illegal practice, assures the quality of dental education and investigates complaints. ${ }^{1}$ The NHS Area Teams (ATs) and Local Health Boards (LHBs) commission dental services for the NHS and also seek to ensure that services are delivered in accordance with the contract agreed with the provider. In addition, the Care Quality Commission (CQC) monitors, inspects and regulates health and social care services, including dental practices, to make sure they meet fundamental standards of quality and safety. ${ }^{2}$

\footnotetext{
'Dental Researcher; ${ }^{2}$ Research Fellow in Medical Education; ${ }^{3}$ Associate Dean for Conduct and Performance: ${ }^{4}$ Dean of Postgraduate Dental Education, Health Education England (North West), 3rd Floor, 3 Piccadilly Place, Manchester, M1 3BN

*Correspondence to: Mr Mark Pearce

Email: oliver.pearce@tiscali.co.uk
}

\section{Refereed Paper}

Accepted 3 March 2016

DOI: 10.1038/sj.bdj.2016.326

${ }^{\circ}$ British Dental Journal 2016; 220: 443-446
A patient can complain to one or more of these organisations about the care they have received. A colleague may report unprofessional behaviour to the GDC and it is, as stated within the GDC's Standards for the dental team, their duty to do this. ${ }^{3}$ The AT may investigate a dentist's clinical practice because there appear to be statistical outlier(s) in their treatment patterns. The CQC may inspect a practice and decide that it is failing to meet its standards. The CQC have for the next year (2015/2016) decided to inspect only $10 \%$ of dental practices, but a proportion of those inspections will be as a result of a risk based assessment rather than random selection. ${ }^{4}$ The raising of a complaint or concern about a practice by an AT, user or an employer could result in an inspection and, if found to be inadequate, a practice could ultimately lose its registration and be unable to operate. Thus it is theoretically possible for a person or persons to complain to the GDC, AT and CQC, and for a registrant to be placed in triple jeopardy.

The number of registrants getting into difficulty has increased significantly in recent years. William Moyes, chair of the GDC, wrote in the 2013 Annual Report and Accounts that since 2010, fitness to practise complaints have increased by $110 \% .^{5}$
This increase might, in part, be explained by the significant increase in the number of GDC registrants in recent years. From July 2008 all dental care professionals (DCPs) had to be registered, not just dentists, and by the end of that year there were 36,281 dentists and 55,926 DCPs. By 2014 there had been further increases to 41,038 dentists and 65,275 DCPs. ${ }^{6,7}$ Even so, in 2008 there were only 164 cases, representing a percentage for all registrants of $0.18 \%$, referred to a practice committee for a public hearing whereas in 2014 there were 403 cases or $0.38 \%$ of all registrants. To the consternation of the profession, the GDC has also, in the past few years, posted adverts in the national newspapers explaining to patients how to complain to it about poor dental care. ${ }^{8}$

The majority of issues considered by the GDC Professional Conduct Committee (PCC) or Professional Performance Committee (PPC) were related to either poor clinical care or clinical governance. In 2014 they considered 94 cases where poor clinical treatment was an issue and 66 relating to poor clinical records, but only six where conviction or police caution relating to theft or fraud was an issue, and five for assault. ${ }^{7}$ Depending on the nature of the impairment, the GDC or AT may decide to impose appropriate conditions 
on a registrant's practice with the aim of improving it such that patients are no longer put at risk. One of these conditions for continued practice may be an instruction to contact the postgraduate dental teams (PgDT) based in regional offices of Health Education England (HEE) and equivalent postgraduate deaneries in Wales and Scotland for assistance. In Northern Ireland DRiDs are referred to NCAS for assesment. ${ }^{9}$

If a dentist gets into difficulty then they may also be advised by a defence organisation, colleague or other source, that they should contact their PgDT for help before any hearing. One reason for this may be to demonstrate that they have insight with regard to their difficulty and that they are making every effort to address it ahead of any hearing. In this way they aim to make a favourable impression and thereby influence the decision made by the GDC or AT during a substantive hearing about their continued practice.

Thus, PgDT across the UK are helping an increasing number of registrants in difficulty (DRiDs) and have had to rapidly develop the service. There is, however, very little information in the public domain on the nature of these services or whether there is parity of provision for DRiDS across the UK. The authors therefore devised a survey which was distributed electronically to the managers of the service for DRiDs at all PgDT across HEE and both Welsh and Scottish deaneries asking for information on the management structure, funding, educational supervision, number of mentors and clinical supervisors, recruitment procedures, training, work load, other agencies used and the views of the managers on the strengths, weaknesses and future development of the service. Ten out of a possible 12 organisations responded.

\section{HOW ARE SERVICES FOR REGIS- TRANTS IN DIFFICULTY CURRENTLY BEING MANAGED?}

The survey showed that the service was being managed by senior educators devoting, on average, seven hours to the task per week. Ninety percent of respondents had other areas of responsibility in addition to DRiDs. These DRiDs Leads reported considerable relevant previous experience which underpinned their responsibility for DRiDs, with many having over 30 years of dental practice augmented by a range of longstanding training and practitioner support roles. The majority had undertaken formal training and/or certification in one or more of mentoring, counselling, coaching and appraisal. In addition, many respondents held advisory roles relating to, for example, NCAS, clinical governance and quality improvement.
Table 1 Number of registrants supported with performance issues in 2013

\begin{tabular}{l|l|l}
\hline Reason for request for assistance & Median number from 10 PgDT & Range \\
\hline Self-referral (preconditions) & 6.5 & $0-32$ \\
\hline Self-referral (no conditions) & 2.5 & $0-5$ \\
\hline GDC & 3 & $0-12$ \\
\hline LAT/LHB (PCT) & 3 & $0-23$ \\
\hline NCAS & 0 & $0-1$ \\
\hline Return to work & 0 & $0-2$ \\
\hline Professional colleague & 0 & $0-1$ \\
\hline Corporate body & 0 & $0-1$
\end{tabular}

\section{RISING DEMAND FOR SERVICES}

The PgDT were asked how many dentists had presented to them in specified categories over the past five years to allow for an analysis of how demand for the service had changed. However, such has been the pace of change that these data had not been collected in a significant number of regions and for this reason the data are presented for 2013 only in Table 1.

The biggest source of requests for assisconcern who were seeking help before official organisations had met, identified as 'Self-referral (preconditions)' in the table, followed by those with conditions imposed by ATs and then the GDC. It is relevant to note the significant differences in numbers seeking assistance between the PgDT with some areas recording no cases and others more than 20 with conditions imposed by the ATs and more than 30 with preconditions for 2013.

The regional DRiDs Leads reported that under normal circumstances, following a referral, all registrants would be seen by tance was from dentists with a recognised someone from their regional PgDT within a four week period and in half of the responding organisations the response was within two or three weeks. It is important for both practical and psychological reasons that DRiDS are seen as quickly as possible. An increase of time beyond four weeks for an initial interview would suggest that a service may be under resourced or needing to be organised differently.

\section{PROFESSIONAL SUPPORT FOR DRIDs}

As a result of the initial interview, or in the light of subsequent developments, a DRiDs Lead may appoint a colleague to help a DRiD. These supporters are appointed by the PgDT to fulfil a variety of roles and the DRiDs Leads were asked to indicate what type of supporter they had appointed for each DRiD over the past five years (though we acknowledge that there is currently no agreed definition of the role of each type). For all the various categories of supporters at least one PgDT had, in each instance, appointed none; while Figure 1 shows that some PgDTs had

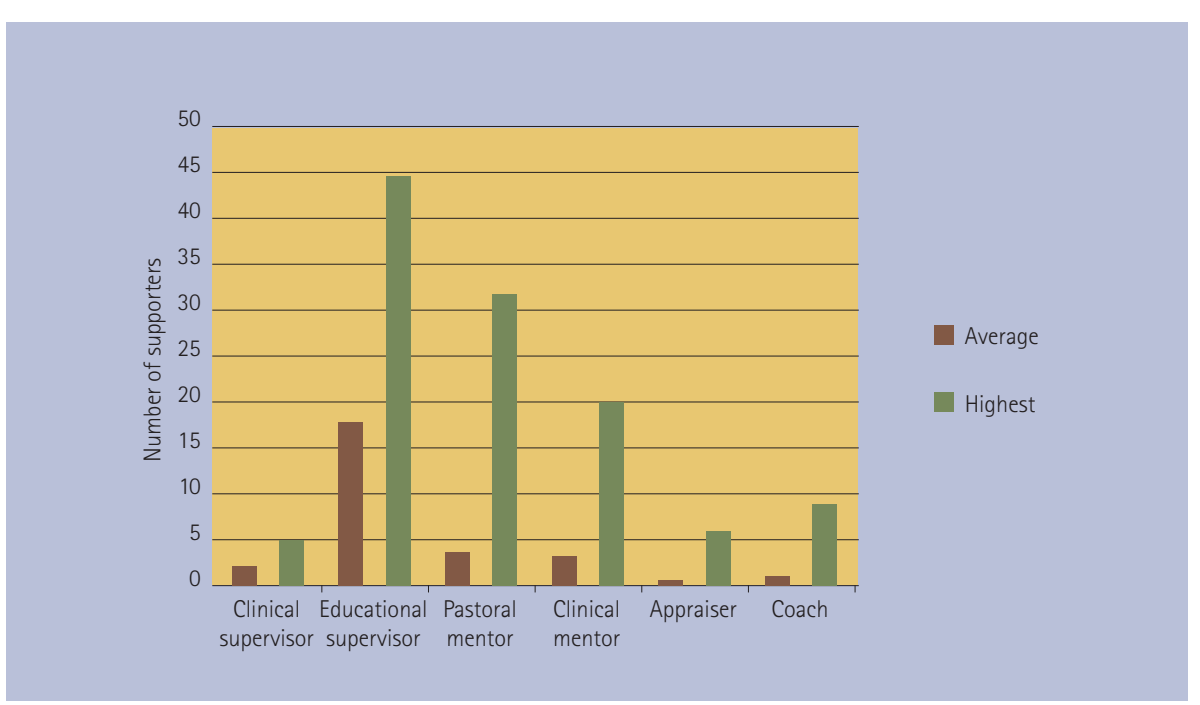

Fig. 1 Total number of supporters needed in the past five years, split into the type of supporter required 
appointed a significant number of educational supervisors and mentors.

When asked to comment on the recruitment of supporters, some had only a low level of demand and little need to recruit: 'Due to the relatively small numbers of DRiDs we seem to manage.' Others appeared to have a well-developed process for recruitment: 'We are robust in our appointment process - it follows an application, three days of training and a day assessment before an offer is made.'

When recruiting for the role, organisations sought NHS clinicians who were currently active with considerable experience as dental practitioners, educators, appraisers and mentors. Some specified a postgraduate education qualification. With regard to specific qualities which were considered important for the role, empathy, integrity and excellent verbal/written communication skills were the most commonly cited. A number of respondents emphasised the importance of teaming these qualities with strong abilities in concise, logical, action planning, and a firm but fair approach to providing support for registrants.

There was considerable disparity in the training and ongoing support provided or sourced by the individual PgDT for supporters in this role. The majority organised access to training in mentoring while two had a three day introductory course. Others sourced training in appraisal and counselling and coaching for performance. Some supporters had secured additional training independently, including in cognitive behavioural therapy and professional educator courses. Regular supervision, appraisal and advice from more experienced coaches/ mentors were available to some supporters and some were encouraged to attend annual refresher courses and regular peer group meetings to share good practice.

\section{CONSTRAINTS ON EXISTING SERVICES}

A wide range of services could be sourced for DRiDs, including initial assessment, counselling, health screening, CPD courses, communication skills, mentoring, observation of practice, assessment of clinical skills, clinical simulation, shadowing facilities, tailored clinical and/or generic skills training, and supervision for return-to-practice schemes. However, these facilities were not available to all and most respondents reported a need to make at least minor changes in order to enhance provision of such services. While service providers were well trained and committed, the increasing numbers of DRiD referrals was putting a strain on already stretched services in many regions.
An improved infrastructure, particularly in terms of access to additional clinical supervision and clinical training facilities, would be particularly welcome.

Other reported constraints on the delivery of PgDT services to DRiDs included:

- Absence of consistent processes across the regions

- Difficulties in finding practices willing to offer positions to DRiDs who are out of work

- Reluctance or inability on the part of some registrants to pay for the services available

- Increasing number of referrals from indemnity organisations ahead of possible hearings.

\section{IMPROVEMENTS TO SERVICE DELIVERY}

Respondents suggested a range of methods to improve the delivery of their services to DRiDs. Other than the additional time, clinical support and dedicated clinical training facilities already mentioned suggestions included:

- Direct early contact from indemnity organisations which should take more responsibility for managing the process before conduct committee hearings as many referrals came very late

- Regular communication networks

- Group sessions for common issues (for example, PDP planning)

- The addition of an occupational health/ psychiatric assessment to support DRiDs experiencing depression during remediation.

Most regions were supportive of greater standardisation of processes for supporting DRiDs across the country, including a COPDEND national framework to ensure an equitable service, a formal referral process with clear lines of management and agreed protocols for reporting and monitoring. For example, the majority of teams did not charge for the initial meeting with a DRiD. Some registrants had subsequent support meetings funded while the remainder had to pay for this personally. It would be more equitable for DRiDs if the same policy around charging was applied across all teams. A number of meetings of managers with responsibility for DRiDs have taken place over the past year and this has led to the recent updating of the COPDEND policy document Remediation of Dental Registrants in Difficulty. Guidance notes on the management of remediation cases referred to Dental Postgraduate Organisations. ${ }^{10}$

In the survey, DRiDs Leads identified a total of 21 DRiDs who were unable to meet their conditions. This may be for a number of reasons including poor physical or mental health, addiction, or simply an inability to find employment. Such DRiDs have the double barrier of being unable to demonstrate clinical competence and potentially being unable to afford the support of the PgDT. Perhaps some thought needs to be given to a national policy on how such DRiDS should be supported.

Support services are not the same across the PgDT. In particular, many DRiDs Leads indicated a desire for access to more clinical and other generic skills training facilities. This type of training facility can be difficult to set up and expensive to run and may not be viable when an individual PgDT is supporting only one or two DRiDs. The most common concerns considered by the Professional Performance Committee and Professional Conduct Committee of the GDC were poor treatment and also poor record keeping, and a failure to take appropriate radiographs. ${ }^{7}$ Thus, DRiDs may often need guidance with more than one aspect of their practice. Establishing one or two centres with expertise in the UK where any DRiD, irrespective/of his or her geographical location, could be assessed and undergo remedial training in many aspects of professional practice, may be a way of harmonising services in a cost-effective way. Indeed, those who actually get into difficulty are surely only a small proportion of all who would benefit from hands-on training in clinical skills, and/or clinical governance that could be provided by a suitably designed training facility. Research has suggested that blended learning involving a number of different teaching methods is the most effective way to bring about a change in practice. ${ }^{11-13}$ The use of such teaching facilities could be an important part of a rehabilitation package.

From our survey data we found evidence of a need for an occupational health/psychiatric assessment for depressed or distressed registrants. Suicides of dentists, and other health care professionals, as a consequence of getting into difficulty have been reported. ${ }^{14-16}$ However, given that the PgDT area of expertise is training/education rather than mental health, should they be involved in this extremely important area? The GMC commissions the BMA to provide this type of service which can accessed by any doctor in difficulty. ${ }^{17}$ Given its current financial situation, it is difficult to imagine the GDC being able to commission an equivalent service. The Dentists' Health Support Programme provides support for dentists with an addiction to alcohol or other drugs giving access to a dentist who is in recovery from an addiction or a clinical psychologist specialising in addiction. ${ }^{18}$ The British Doctors' and Dentists' 
Group is a mutual help group for doctors and dentists who are recovering, or wish to recover, from addiction to, or dependency on, alcohol or other drugs. ${ }^{19}$ Given the increasing number of registrants getting into difficulty perhaps these services could be broadened to include those needing physiological support for a wider range of reasons, or services of a similar character set up.

\section{HARMONISING SERVICES FOR DRIDS ACROSS THE UK}

The response from DRiDs Leads indicates significant differences in the demand for their services across PgDT and that some had well developed processes in place, significant trained man power available to assist DRiDS and training resources to call on, while others had just started to develop their services. It may be useful to investigate the reasons for these differences in greater depth as they might help explain why an increasing number of dentists are seeking help.

There is obvious scope for collaboration between HEE teams with the aim of providing a consistent service across the UK. All interested agencies, including the PgDT, GDC, ATs, CQC and indemnifiers should constantly be seeking ways to further develop the integration of their services to better safeguard patients; but also to interact consistently and efficiently with registrants when there is a problem. Indeed, the GDC states as one of its current corporate strategies that it will also build strong relationships with other regulators to ensure that the regulation of the dental team is as seamless as possible and has jointly established the 'Regulation of Dental Service Programme Board' with the NHS, the Care Quality Commission, NHS Business Services Authority and Healthwatch England to promote coordination, consistency, to avoid overlap, and to better understand risk..$^{20}$

We plan to report on further research we have carried out using the views of DRiDs on the support they currently receive from all sources and the views of those supporting DRiDs, as well as the DRiDS, on how to prevent difficulties occurring and efficiently manage them when they do.

\section{RAISING CONCERNS}

If the performance of a colleague is causing concern then it is important to address it as soon as possible both for the safety of patients and also, where possible, to expedite the remediation of the registrant. The raising of a complaint should not be undertaken lightly and the details of the problem should be recorded and the matter discussed with the registrant, senior colleagues, ATs and your indemnifier as appropriate. However, if, after due consideration, it is felt that the registrant should be reported, the GDC has published a leaflet on how to do this. ${ }^{21}$

The authors would like to thank the postgraduate dental deans and directors and those responsible for managing the service for DRiDs within PgDTs for their support in the development of this project and in responding to the questionnaire.

1. The General Dental Council. About us. Available online at http://www.gdc-uk.org/Aboutus/Pages/ default.aspx (accessed February 2016).

2. Care Quality Commission. Who we are. Available online at http://www.cqc.org.uk/content/who-weare (accessed February 2016).

3. The General Dental Council. Standards for the dental team. pp 70-76. London: HMSO, 2013, Available online at http://www.gdc-uk.org/Dentalprofessionals/Standards/Documents/Standards\%20for\%20 the\%20Dental\%20Team.pdf (accessed February 2016).

4. Care Quality Commission. How CQC regulates Primary Care Dental services: Provider hand book. 2015. http://www.cqc.org.uk/sites/default/ files/20150611_dental_care_provider_handbook. pdf (accessed September 2015).

5. General Dental Council. Annual report and accounts 2013. London: HMSO, 2014. Available online at http://www.gdc-uk.org/Newsandpublications/Publications/Publications/GDC\%20AR\%202013\%20 FINAL\%20WEB.pdf (accessed September 2015).

6. General Dental Council. Annual review 08. London: GDC, 2008. Available online at http://www.gdc-uk. org/Newsandpublications/Publications/Publications/AnnualReview08web.pdf (accessed February 2016).

7. General Dental Council. Annual report and accounts 2014. London: HMSO, 2015. Available on line at
http://www.gdc-uk.org/Newsandpublications/ Publications/Publications/17290\%20GDC\%20 AR\%20ACC\%202014\%20R6\%20WEB\%20UD.pdf (accessed October 2015).

8. Healthcare-news. Dental profession outraged by GDC's Telegraph advert. Available online at http:/I www.smile-onnews.com/news/view/dental-profession-outraged-by-gdcs-telegraph-advert (accessed April 2016).

9. A Morrow G, Burford B, Kergon C, Illing J. Addressing performance concerns. Br J Healthcare Manage 2010; 16: 436-442.

10. Committee of Postgraduate Dental Deans and Directors. Remediation of Dental Registrants in Difficulty. Guidance notes for the management of remediation cases by Dental Postgraduate Organisations. September 2009, revised January 2014. Available online at http://www.copdend.org/ data/files/Site\%20Docs/Remediation\%20of\%20 Dental\%20Registrants\%20in\%20Difficulty\%20 v7\%20-\%20January\%202014.pdf (accessed September 2015)

11. Eaton K, Brookes J, Patel R, Batchelor P, Merali F, Narain A. The Impact of continuing professional development in dentistry: a literature review. London: General Dental Council, 2011.

12. Grol R, Grimshaw J. From best evidence to best practice: effective implementation of change in patients' care. Lancet 2003; 362: 1225-1230.

13. Barnes E, Bullock A D, Bailey S E R, Cowpe J G, Karaharju-Suvanto T. A review of continuing professional development for dentists in Europe. Eur J Dent Educ 2012; 16: 166-178.

14. Renshaw J. Dentist suicides. Br Dent J 2013; 215 593-594.

15. Mc Crory P V. Dentist suicides. Br Dent J 2014; 216: 436.

16. Sprinks J. RCN will offer mentor support to nurses facing misconduct charges. Nurs Stand 2012; 27: 5 .

17. British Medical Association. Doctor Support Service. Available online at. http://www.bma.org.uk/ support-at-work/doctors-well-being/doctor-support-service (accessed December 2014).

18. The Dentists Health Support Programme Helpline. Available online at http://sick-doctors-trust.co.uk/ page/dentists-health-support-programme-helpline (accessed September 2015).

19. The British Doctors and Dentists Group. Available online at http://www.bddg.org/ (accessed September 2015).

20. General Dental Council. Corporate Strategy. 2010-2014. London: GDC, 2010. Available online at http://www.gdc-uk.org/Newsandpublications/ Publications/Publications/GDC\%20Corporate\%20 Strategy\%202010-14.pdf (accessed September 2015).

21. General Dental Council. How to report a dental professional to us. Available online at http://www. gdc-uk.org/Newsandpublications/Publications/ Publications/HowtoReportEnglishfinal\%5B1\%5D. pdf (accessed February 2016). 